\title{
The glycaemic response to rolled oat is not influenced by the fat content
}

\author{
Saska Tuomasjukka ${ }^{1 *}$, Matti Viitanen ${ }^{2}$ and Heikki Kallio ${ }^{1}$ \\ ${ }^{1}$ Department of Biochemistry and Food Chemistry, University of Turku, 20014 Turku, Finland \\ ${ }^{2}$ Geriatrics, University of Turku, 20014 Turku, Finland
}

(Received 8 June 2006 - Revised 2 November 2006 - Accepted 16 November 2006)

\begin{abstract}
Oat is promoted as a low-glycaemic index food. Our aim was to measure the effect of the fat content of oat in glycaemia and insulinaemia and compare it with the effect of wheat. The study design was a double-blind, randomised cross-over study with four treatment segments. Eight healthy males attended four study sessions in which porridge made from four different raw materials was consumed: rolled oat (O), defatted rolled oat (DO), rolled whole wheat (W) or rolled whole wheat with added oat fat (WF). Available carbohydrate content was analysed enzymatically, and was adjusted to $50 \mathrm{~g}$ in each test meal. Fat content per meal was either $6.1 \mathrm{~g}(\mathrm{O}, \mathrm{WF})$ or approximately $1.9 \mathrm{~g}(\mathrm{~W}, \mathrm{DO})$. Venous plasma glucose, insulin and triacylglycerol concentrations were measured at $0,30,60,90,120$ and $180 \mathrm{~min}$. All products caused a rapid increase in glucose with a peak at $30 \mathrm{~min}$, where $\mathrm{W}$ and $\mathrm{WF}$ were significantly higher than $\mathrm{O}(0=0 \cdot 006)$. Also insulin peaked at $30 \mathrm{~min}$ (no differences). A $4 \cdot 2 \mathrm{~g}$ difference in fat content between $\mathrm{O}$ and DO or W and WF did not result in any significant differences in their glycaemia or insulinaemia. W and $\mathrm{O}$ did not differ in their overall glycaemic or insulinaemic responses. The removal of two-thirds of oat fat did not affect the postprandial plasma triacylglycerol concentration. The present study shows that neither the glycaemic nor the insulinaemic response to rolled oat is affected by the fat content, and that rolled wheat differed from rolled oat in terms of peak glucose concentration only.
\end{abstract}

Oat: Wheat: Fat: Glycaemia: Insulinaemia

Accumulating evidence supports the therapeutic potential of low-glycaemic index (GI) diets in the prevention and treatment of diabetes (Jenkins et al. 1987; Salmeron et al. $1997 a, b)$. Oat is currently advocated as a low-GI food. The GI of various oat products varies between 42 and 80, conventional oat porridge having a value of 58 (Foster-Powell et al. 2002). The low GI of oat has been partially explained by the high content of soluble $\beta$-glucan, which is known to blunt the increase in plasma glucose and insulin concentrations after a carbohydrate meal. This is mainly attributed to the delay and lengthening of the carbohydrate absorption time due to an increase in viscosity and a decrease in the starch digestion rate (Battilana et al. 2001).

Fat is well known to lower the glycaemic response to foods (Collier \& O'Dea, 1983; Welch et al. 1987). Compared with most other cereal products, oat contains a considerable amount of fat (approximately 7\%) (Anonymous, 2005, 2006). Fat may also indirectly affect the results of the GI test, as the enzymatic analysis of available carbohydrate is usually influenced by high fat content.

We hypothesised that the low GI of oat could at least partially result from its fat content. We first carefully measured the available carbohydrate content in oat and wheat and then tested the glycaemic response to porridge made from conventional and defatted rolled oat, and compared it with similar products made from whole wheat alone and in combination with oat fat.

\section{Subjects and methods \\ Subjects}

Nine healthy males with fasting glucose, triacylglycerol and cholesterol concentrations within the recommended values, and with no family history of cardiovascular diseases or diabetes, were recruited for the study (Table 1). During the study, one subject showed increased fasting glucose values, and was excluded from the data. Informed consent was obtained from each participant. The study protocol was approved by the Ethical Committee of the University Hospital of Turku.

\section{Test meals}

Each subject received four test meals in a random order. The study sessions were arranged with $2-7 \mathrm{~d}$ intervals. The products were porridge made from rolled oat $(\mathrm{O})$ (Helsingin Mylly, Vaasa, Finland), rolled defatted oat (DO), rolled whole wheat (W) (Raisio, Raisio, Finland) and rolled whole wheat and oat fat (WF). All grains were organically produced.

\footnotetext{
Abbreviations: DO, defatted rolled oat; GI, glycaemic index; iAUC, incremental area under the curve; O, rolled oat; W, whole wheat; WF, whole wheat with added oat fat.

* Corresponding author: Saska Tuomasjukka, M.Sc., fax: +358 2333 6860, email saska.tuomasjukka@utu.fi
} 
Table 1. Fasting clinical data of subjects participating in the study $(n 8)$

(Mean values and standard deviation)

\begin{tabular}{lrc}
\hline & Mean & SD \\
\hline Age, years & 21.3 & 2.7 \\
BMl $\left(\mathrm{kg} / \mathrm{m}^{2}\right)$ & 22.6 & 1.8 \\
Glucose $(\mathrm{mmol} / \mathrm{l})$ & $5 \cdot 1$ & 0.4 \\
Triacylglycerols $(\mathrm{mmol} / \mathrm{l})$ & 0.7 & 0.3 \\
Cholesterol $(\mathrm{mmol} / \mathrm{l})$ & 3.7 & 0.4 \\
HDL $(\mathrm{mmol} / \mathrm{l})$ & 1.5 & 0.2 \\
LDL $(\mathrm{mmol} / \mathrm{l})$ & 1.9 & 0.4 \\
\hline
\end{tabular}

DO was produced from $\mathrm{O}$ by industrial scale $\mathrm{CO}_{2}$ extraction which efficiently extracts non-polar fat (Aromtech, Tornio, Finland), and the extracted oat fat was combined with $\mathrm{W}$ to produce WF. Each portion contained $50 \mathrm{~g}$ of available carbohydrate. The fat contents of the portions were $6.1 \mathrm{~g}(\mathrm{O}$ and WF), $1.9 \mathrm{~g}$ (DO) or $1.8 \mathrm{~g}(\mathrm{~W})$. The porridge was prepared just minutes before consumption in a microwave oven by cooking an appropriate amount with $500 \mathrm{ml}$ of water first at full power $(700 \mathrm{~W})$ until it began to boil, followed by $2 \mathrm{~min}$ at $300 \mathrm{~W}$.

The fat content of $\mathrm{W}, \mathrm{O}$ and DO was measured by modified Folch extraction (Folch et al. 1957). The available carbohydrate was measured with an amyloglucosidase/thermostable $\alpha$-amylase method (AACC 76.13) (Total Starch, Megazyme, Bray, Ireland) from $\mathrm{W}$ and from $\mathrm{O}$ exhaustively defatted by chloroform-Soxhlett extraction. Protein was measured by the Kjeldahl method from $\mathrm{W}$ and $\mathrm{O}$ using 5.83 as the conversion factor. Carbohydrate and protein content of the other raw materials was derived by calculation from the values of $\mathrm{O}$ and $\mathrm{W}$. The nutrient content is presented in Table 2. Oat oil fatty acid methyl esters were produced with boron trifluoride (Morrison \& Smith, 1964) and analysed by GC-FID (Perkin-Elmer Autosystem, Boston, MA) with a J\&W DB23 column $(60 \mathrm{~m} \times 0.32 \mathrm{~mm}$ id, $0.25 \mu \mathrm{m}$ film (Agilent, Folsom, CA)) (Table 3).

\section{Study design}

Subjects were asked to avoid strenuous exercise for $48 \mathrm{~h}$ prior to the test, and were provided with a standardised medium-fat meal for consumption on the evening before the test day.
Subjects attended the trial site at 08.00 after a $12 \mathrm{~h}$ fast. An intravenous cannula was placed in a forearm vein and a basal blood sample was drawn $(0 \mathrm{~min})$. Each day, the test meal was served at the same time (08.00-08.30) with instructions to eat it within $10 \mathrm{~min}$. Additional blood samples were taken at 30, 60, 90, 120 and $180 \mathrm{~min}$. Plasma was immediately separated by centrifugation. Triacylglycerol and glucose were determined by enzymatic colorimetric methods (Roche Diagnostics, Mannheim, Germany) using an automated instrument (Hitachi 917 Automatic Analyzer, Hitachi, Tokyo, Japan). Plasma insulin was measured using time-resolved fluoroimmunoassay (Wallac, Turku, Finland). The incremental area under the curve (iAUC) from 0 to 120 or to $180 \mathrm{~min}$ was calculated using the trapetzoidal method (Matthews et al. 1990) by excluding the area below baseline, and was expressed as $\mathrm{pmol} / \mathrm{h}$ per litre (insulin) or $\mathrm{mmol} / \mathrm{h}$ per litre (glucose). For triacylglycerol, similar calculations were made, but as the incremental values were mostly negative, the area below the baseline was included ( $\mathrm{mmol} / \mathrm{h}$ per litre).

\section{Statistical analysis}

In this randomised double-blind trial, each subject consumed four test meals and served as his own control. Paired samples $t$ test (with Bonferroni correction) was used for testing the differences in plasma time points, time series and iAUC. A statistical difference of $P<0.05$ was deemed significant. Analyses were carried out with SPSS (Chicago, IL, USA). Values are expressed as the mean of eight determinations. All data were log-transformed prior to analysis.

\section{Results}

The fat content of $\mathrm{W}, \mathrm{O}$ and DO were $2.1 \%$ (SD 0.1), $6.4 \%$ (SD $0 \cdot 1$ ) and $2 \cdot 1 \%$ (SD $0 \cdot 2$ ), respectively. The available carbohydrate and the Kjeldahl protein for $\mathrm{W}$ and $\mathrm{O}$ were $57.6 \%$ (SD 1.2 ) and $12.5 \%(\mathrm{SD} 0.0), 52.4 \%(\mathrm{SD} 1.5)$ and $13.1 \%(\mathrm{SD} 0.2)$, respectively (Table 2 ).

Fasting and postprandial plasma contents of glucose, insulin and triacylglycerol are given in Table 4. Incremental responses to the meals are shown in Fig. 1. All the products caused a similar rapid increase in glucose and insulin, with a peak at $30 \mathrm{~min}$ in all but five cases (one subject for glucose and four subjects for insulin had a peak at $60 \mathrm{~min})$. W and WF

Table 2. Nutrient composition of the raw materials and portions consumed (Values are presented as the mean (and standard deviation) of three analyses per $100 \mathrm{~g}$ of product)

\begin{tabular}{|c|c|c|c|c|c|c|c|c|}
\hline & \multicolumn{2}{|c|}{$W(g / 100 g)$} & \multicolumn{2}{|c|}{ WF $g / 100 \mathrm{~g}$} & \multicolumn{2}{|c|}{$\mathrm{O}(\mathrm{g} / 100 \mathrm{~g})$} & \multicolumn{2}{|c|}{ DO (g/100 g) } \\
\hline & Mean & SD & Mean & SD & Mean & SD & Mean & SD \\
\hline Energy (kJ) & 1269 & & 1378 & & 1350 & & 1234 & \\
\hline Protein $(g)$ & $12 \cdot 5$ & 0.0 & $12 \cdot 0^{*}$ & 0.0 & $13 \cdot 1$ & 0.2 & $13.6 \ddagger$ & 0.2 \\
\hline Available carbohydrate $(\mathrm{g})$ & $57 \cdot 6$ & $1 \cdot 2$ & $55 \cdot 1^{*}$ & $1 \cdot 2$ & $52 \cdot 4 \dagger$ & 1.5 & $54.4 \dagger$ & 1.6 \\
\hline Fat $(\mathrm{g})$ & $2 \cdot 1$ & 0.1 & $6 \cdot 4$ & 0.1 & $6 \cdot 4$ & 0.1 & $2 \cdot 1$ & 0.2 \\
\hline Portion with $50 \mathrm{~g}$ of available carbohydrate $(\mathrm{g})$ & 86.9 & & 91.4 & & 95.4 & & 91.9 & \\
\hline Energy per portion (kJ) & 1103 & & 1258 & & 1288 & & 1134 & \\
\hline
\end{tabular}

W, wheat; WF, wheat + oat fat; O, oat; DO, $\mathrm{CO}_{2}$-defatted oat.

* Derived from $\mathrm{W}$.

† Derived from chloroform-Soxhlett-defatted oat.

$\ddagger$ Derived from $\mathrm{O}$. 
Table 3. Fatty acid composition of oat fat

Values are presented as the mean (and standard deviation) of three analyses

\begin{tabular}{lcc}
\hline Fatty acid & Mean (\%) & SD (\%) \\
\hline $16: 0$ & 16.3 & 0.0 \\
$18: 0$ & 1.8 & 0.0 \\
$18: 1 n-9$ & 39.2 & 0.0 \\
$18: 2 n-6$ & 38.9 & 0.0 \\
$18: 3 n-3$ & 1.5 & 0.0 \\
Other & 2.3 & 0.0 \\
\hline
\end{tabular}

caused a higher glycaemic peak at $30 \mathrm{~min}$ than $\mathrm{O}(P=0 \cdot 006)$, but no difference was found at later time points. Insulin concentrations did not differ at any of the time points. Neither the iAUC of glucose or insulin nor the corresponding insulin: glucose ratio differed between any of the test meals.

For the triacylyglycerol concentration, there were no statistically significant differences in the time points or in the iAUCs. However, the triacyglycerol concentration after DO were consistently lower than those after $\mathrm{O}$.

\section{Discussion}

Oat is appreciated as a low-GI food, with a current GI value of 58 (oat porridge) (Jenkins et al. 1981; Foster-Powell et al. 2002). Ever since Jenkins introduced GI as a basis for carbohydrate exchange in 1981, it has been acknowledged that the addition of fat to the carbohydrate load slows gastric emptying and reduces the glycaemic response (Jenkins et al. 1981). However, the role of the relatively high fat content of oat in its low GI has not been studied.

We found that lowering the fat content of oat to the level of that of wheat did not change the glycaemia or insulinaemia following the ingestion of $50 \mathrm{~g}$ of oat carbohydrate (glucose and insulin iAUC for $\mathrm{O}$ and DO were 1.01 (SD 0.63) and 35.2 (SD 13), 0.93 (SD 0.40) and 37.2 (SD 14), respectively). This is in contrast to several studies demonstrating that fat can lower the glycaemic response to foods (Welch et al. 1987; Collier et al. 1988; Gannon et al. 1993b). However, $>15 \mathrm{~g}$ of fat has generally been required for a significant decrease, when at least $50 \mathrm{~g}$ of carbohydrates is consumed (Gatti et al. 1992; Normand et al. 2001; Owen \& Wolever, 2003). Unsaturated fats have been shown to be especially effective in blunting the glucose response (Gatti et al. 1992), but in our study the highly unsaturated oat fat did not show this effect. An important finding of the present study was thus the observation that when $4.2 \mathrm{~g}$ of fat ( $69 \%$ of total) is removed from a standard $50 \mathrm{~g}$ portion of oat carbohydrate, the postprandial glycaemia is not affected. It seems likely that the low GI of oat does not result from its fat content.

Further support for the observed no-effect level was obtained from the addition of $4.2 \mathrm{~g}$ of oat fat to wheat, which did not result in any statistically significant change in glucose or insulin iAUC or peak concentration. The potentiation of insulin secretion by the co-ingestion of fat is well established (Collier \& O'Dea, 1983; Collier et al. 1984; Gannon et al. 1993a,b), but in healthy subjects it has only been shown with substantially higher fat loads $(37.5 \mathrm{~g})$ (Collier et al. 1984) than used in the present study. With non-insulin-dependent diabetic subjects, the addition of $15 \mathrm{~g}$ of fat has sufficed (Gannon et al. 1993a). In the present study, the WF insulin peak at $30 \mathrm{~min}$ was approximately $15 \%$ higher than that of $\mathrm{W}$, but the difference was not statistically significant. Venous blood yields glycaemic and insulinaemic results similar to those of capillary blood (Jackson et al. 1983; Wolever et al. 1988), but the latter has better accuracy and enables the detection of a smaller difference (Granfeldt et al. 1995) by reducing the within-subject variation (Wolever et al. 2003). It is therefore possible that the observed levels of glycaemia could have been statistically significantly different, if capillary samples had been collected in the present study.

Table 4. Metabolic responses of eight healthy males to porridge meals with $50 \mathrm{~g}$ of available carbohydrate and approximately $1.9 \mathrm{~g}(\mathrm{~W}, \mathrm{DO})$ or $6.1 \mathrm{~g}(\mathrm{O}, \mathrm{WF})$ of fat

(Mean values and standard deviation)

\begin{tabular}{|c|c|c|c|c|c|c|c|c|}
\hline \multirow[b]{2}{*}{ Test meal } & \multicolumn{2}{|c|}{$\mathrm{O}$} & \multicolumn{2}{|c|}{ DO } & \multicolumn{2}{|c|}{ W } & \multicolumn{2}{|c|}{ WF } \\
\hline & Mean & SD & Mean & SD & Mean & SD & Mean & SD \\
\hline Available carbohydrate (g) & $50 \cdot 0$ & & $50 \cdot 0$ & & $50 \cdot 0$ & & $50 \cdot 0$ & \\
\hline Fat $(g)$ & $6 \cdot 1$ & & 1.9 & & 1.8 & & $6 \cdot 1$ & \\
\hline \multicolumn{9}{|l|}{ Fasting } \\
\hline Glucose (mmol/l) & $5 \cdot 2$ & 0.17 & $5 \cdot 3$ & 0.37 & $5 \cdot 1$ & 0.42 & $5 \cdot 1$ & 0.48 \\
\hline Insulin (pmol/l) & $5 \cdot 6$ & $2 \cdot 4$ & $6 \cdot 9$ & $2 \cdot 7$ & $5 \cdot 5$ & $1 \cdot 0$ & $5 \cdot 0$ & $2 \cdot 2$ \\
\hline Triacylglycerol (mmol/l) & 0.71 & 0.43 & 0.87 & 0.32 & 0.75 & 0.33 & 0.78 & 0.30 \\
\hline \multicolumn{9}{|l|}{ Peak (30 min) } \\
\hline Glucose $(\Delta \mathrm{mmol} / \mathrm{l})$ & 1.7 & 0.35 & 1.8 & 0.40 & $2 \cdot 0$ & $0.37^{\star}$ & $2 \cdot 1$ & $0.42^{*}$ \\
\hline Insulin $(\Delta \mathrm{pmol} / \mathrm{l})$ & 39.4 & 17 & 39.4 & 15 & 41.5 & 23 & $47 \cdot 8$ & 26 \\
\hline \multicolumn{9}{|l|}{ IAUC } \\
\hline Glucose (mmol l/h per litre) & 1.01 & 0.63 & 0.93 & 0.40 & $1 \cdot 20$ & 0.62 & $1 \cdot 17$ & 0.44 \\
\hline Insulin (pmol I/h per litre) & $35 \cdot 2$ & 13 & $37 \cdot 2$ & 14 & 38.6 & 15 & $40 \cdot 1$ & 18 \\
\hline Triacylglycerol $120 \mathrm{~min}(\mathrm{mmol} \mathrm{h} / \mathrm{l})$ & -0.019 & 0.19 & -0.061 & 0.17 & -0.049 & 0.16 & -0.065 & 14 \\
\hline Triacylglycerol $180 \mathrm{~min}(\mathrm{mmol} \mathrm{h} / \mathrm{l})$ & -0.03 & 0.28 & $-0 \cdot 13$ & 0.32 & -0.10 & 0.28 & -0.12 & 0.21 \\
\hline Insulin:glucose & $42 \cdot 8$ & 22 & 44.6 & 20 & $36 \cdot 8$ & 16 & 39.4 & 26 \\
\hline
\end{tabular}

W, wheat; WF, wheat + oat fat; O, oat; $\mathrm{DO}, \mathrm{CO}_{2}$-defatted oat; iAUC, incremental area under the curve.

${ }^{*}$ Significantly different from $\mathrm{O}(P=0.006)$. 

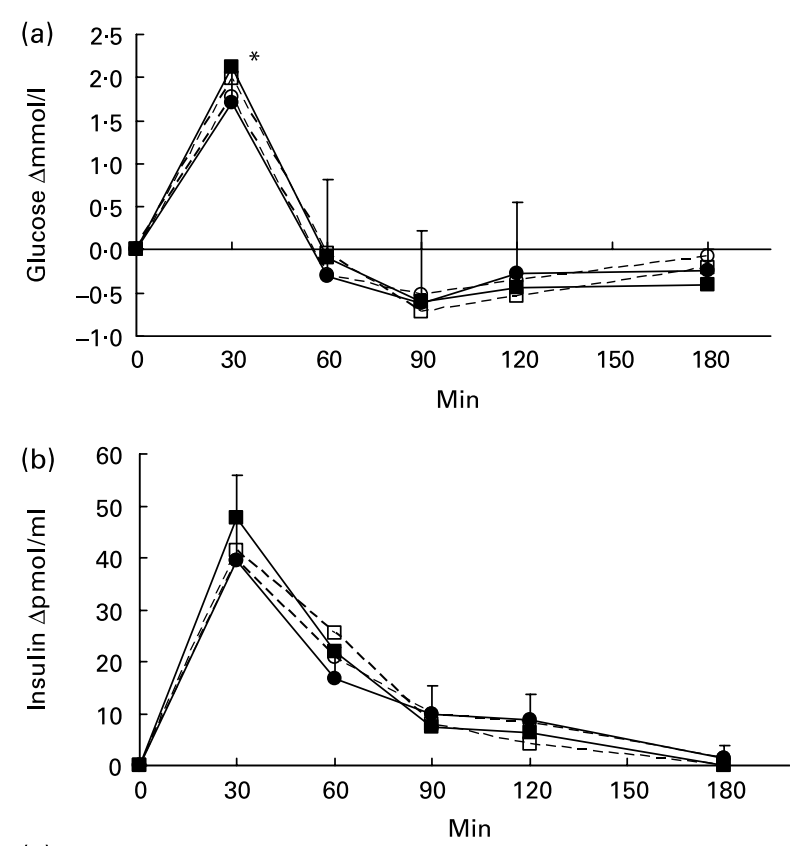

(c)

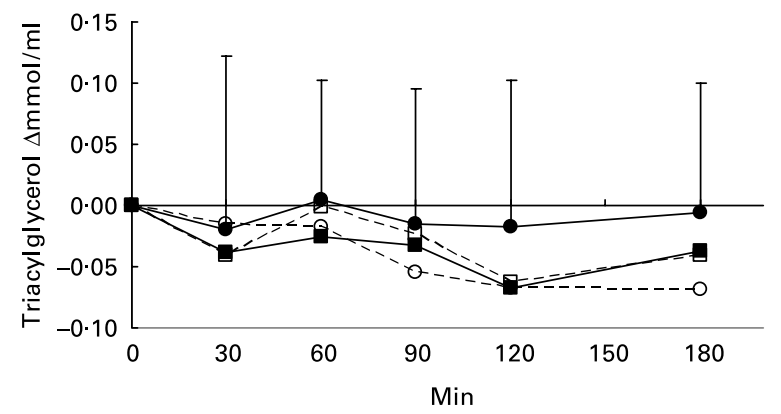

Fig. 1. Blood glucose (a), insulin (b) and triacylgycerol (c) increments after the test meals. Values are presented as a mean of eight subjects. Standard deviation is depicted for $\mathrm{O}$ only for the sake of clarity. - - $\square-$ - , wheat; - - oat; - - O - -, $\mathrm{CO}_{2}$-defatted oat; - - -, wheat + oat fat. *Wheat and wheat + oat fat differ significantly from oat $(P=0.006)$.

The difference between the glucose iAUC of $\mathrm{O}$ and $\mathrm{W}$ was not statistically significant. This is in line with the study by Granfeldt et al. (1995) on kernel porridges. Heaton et al. studying the effects of rolled cereal porridges, found that oat evoked smaller glucose and insulin responses than wheat (Heaton et al. 1988). A likely explanation for the discrepancy lies in the dosage; utilising the analysis of available carbohydrate, we, like Granfeldt et al. (1995), used doses of between 83 and $95 \mathrm{~g}$ (both in agreement with the current Finnish Food Composition Database (Anonymous, 2006)), whereas studies utilising carbohydrate by deduction have used clearly lower portion sizes, varying between 69 and $73 \mathrm{~g}$ (Jenkins et al. 1983; Heaton et al. 1988; Miller et al. 1992). It should be noted, however, that the oat:wheat iAUC ratio in the present study $(1 \cdot 19)$ is in line with the corresponding oat and wheat porridge GI ratio (from 1.14 to 1.28 ) (Foster-Powell et al. 2002). Although the overall responses did not differ, the peak glycaemia was higher after both $\mathrm{W}$ and WF compared with $\mathrm{O}$.

The differences in triacylglycerol concentration after the different fat loads were contradictory. Reduction of the fat content of oat resulted in a consistently lowered triacylglycerol concentration (though without a statistically significant difference), whereas manipulation of wheat with oat fat did not seem to change the lipaemia. However, the magnitude of increments in triacylglycerol concentration was very low, and thus of no practical relevance. This was expected, since $15 \mathrm{~g}$ or more fat has to be consumed to produce detectable changes in postprandial lipaemia (Dubois et al. 1998).

In conclusion, with $50 \mathrm{~g}$ of available carbohydrate from $\mathrm{O}$ or $\mathrm{W}$, their overall glycaemia and insulinaemia did not differ, but the peak value was significantly lower after $\mathrm{O}$. We found that $4.2 \mathrm{~g}$ of fat dosed with $50 \mathrm{~g}$ of cereal carbohydrate does not affect the glycaemic or insulinaemic responses and has only a minimal effect on the subsequent postprandial triacylglycerolaemia. The role of fat in high-fat, low-GI products should be further investigated because of the well-known deleterious effects it may have on the blood lipids and on the risk of coronary artery disease.

\section{References}

Anonymous (2006) Fineli. Finnish Food Composition Database. Release 6. http://www.fineli.fi ed. Helsinki: National Public Health Institute, Nutrition Unit.

Anonymous (2005) USDA Nutrient Database for Standard Reference, Release 18. http://www.ars.usda.gov/ba/bhnrc/ndl ed. US Department of Agriculture, Agricultural Research Service.

Battilana P, Ornstein K, Minehira K, Schwarz JM, Acheson K, Schneiter P, Burri J, Jequier E \& Tappy L (2001) Mechanisms of action of $\beta$-glucan in postprandial glucose metabolism in healthy men. Eur J Clin Nutr 55, 327-333.

Collier GR, Greenberg GR, Wolever TM \& Jenkins DJ (1988) The acute effect of fat on insulin secretion. J Clin Endocrinol Metab 66, 323-326.

Collier G, McLean A \& O'Dea K (1984) Effect of co-ingestion of fat on the metabolic responses to slowly and rapidly absorbed carbohydrates. Diabetologia 26, 50-54.

Collier G \& O'Dea K (1983) The effect of coingestion of fat on the glucose, insulin, and gastric inhibitory polypeptide responses to carbohydrate and protein. Am J Clin Nutr 37, 941-944.

Dubois C, Beaumier G, Juhel C, Armand M, Portugal H, Pauli AM, Borel P, Latge C \& Lairon D (1998) Effects of graded amounts $(0-50 \mathrm{~g})$ of dietary fat on postprandial lipemia and lipoproteins in normolipidemic adults. Am J Clin Nutr 67, 31-38.

Folch J, Lees M \& Sloane Stanley GH (1957) A simple method for the isolation and purification of total lipids from animal tissues. J Biol Chem 226, 497-509.

Foster-Powell K, Holt SHA \& Brand-Miller JC (2002) International table of glycemic index and glycemic load values: 2002. Am $J$ Clin Nutr 76, 5-56.

Gannon MC, Ercan N, Westphal SA \& Nuttall FQ (1993) Effect of added fat on plasma glucose and insulin response to ingested potato in individuals with NIDDM. Diabetes Care 16, 874-880.

Gannon MC, Nuttall FQ, Westphal SA \& Seaquist ER (1993) The effect of fat and carbohydrate on plasma glucose, insulin, C-peptide, and triglycerides in normal male subjects. J Am Coll Nutr 12, 36-41.

Gatti E, Noe D, Pazzucconi F, Gianfranceschi G, Porri M, Testolin G \& Sitori CR (1992) Differential effect of unsaturated oils and butter on blood glucose and insulin response to carbohydrate in normal volunteers. Eur J Clin Nutr 46, 161-166.

Granfeldt Y, Hagander B \& Bjorck I (1995) Metabolic responses to starch in oat and wheat products. On the importance of food structure, incomplete gelatinization or presence of viscous dietary fibre. Eur J Clin Nutr 49, 189-199. 
Heaton KW, Marcus SN, Emmett PM \& Bolton CH (1988) Particle size of wheat, maize, and oat test meals: effects on plasma glucose and insulin responses and on the rate of starch digestion in vitro. Am J Clin Nutr 47, 675-682.

Jackson RA, Blix PM, Matthews JA, Morgan LM, Rubenstein AH \& Nabarro JDN (1983) Comparison of peripheral glucose uptake after oral glucose loading and a mixed meal. Metabolism 32, 706-710.

Jenkins DJA, Wolever TMS, Jenkins AL, Thorne ML, Lee R, Kalmusky J, Reichert R \& Wong GS (1983) The glycaemic index of foods tested in diabetic patients: a new basis for carbohydrate exchange favoring the use of legumes. Diabetologia 24, 257-264.

Jenkins DJ, Wolever TM, Kalmusky J, Giudici S, Giordano C, Patten R, Wong GS, Bird JN, Hall M, Buckley G, et al. (1987) Lowglycemic index diet in hyperlipidemia: use of traditional starchy foods. Am J Clin Nutr 46, 66-71.

Jenkins DJ, Wolever TM, Taylor RH, Barker H, Fielden H, Baldwin JM, Bowling AC, Newman HC, Jenkins AL \& Goff DV (1981) Glycemic index of foods: a physiological basis for carbohydrate exchange. Am J Clin Nutr 34, 362-366.

Matthews JN, Altman DG, Campbell MJ \& Royston P (1990) Analysis of serial measurements in medical research. $\mathrm{Br}$ Med $J$ 300, 230-235.

Miller JB, Pang E \& Bramall L (1992) Rice: a high or low glycemic index food? Am J Clin Nutr 56, 1034-1036.

Morrison WR \& Smith LM (1964) Preparation of fatty acid methyl esters and dimethylacetals from lipids with boron fluoride-methanol. J Lipid Res 5, 600-608.
Normand S, Khalfallah Y, Louche-Pelissier C, Pachiaudi C, Antoine JM, Blanc S, Desage M, Riou JP \& Laville M (2001) Influence of dietary fat on postprandial glucose metabolism (exogenous and endogenous) using intrinsically (13)C-enriched durum wheat. Br J Nutr 86, 3-11.

Owen B \& Wolever TMS (2003) Effect of fat on glycaemic responses in normal subjects: a dose-response study. Nutr Res 23, $1341-1347$.

Salmeron J, Ascherio A, Rimm EB, Colditz GA, Spiegelman D, Jenkins DJ, Stampfer MJ, Wing AL \& Willett AC (1997a) Dietary fiber, glycemic load, and risk of NIDDM in men. Diabetes Care 20, 545-550.

Salmeron J, Manson JE, Stampfer MJ, Colditz GA, Wing AL \& Willett WC (1997b) Dietary fiber, glycemic load, and risk of non-insulin-dependent diabetes mellitus in women. $\mathrm{J}$ Am Med Assoc 277, 472-477.

Welch IM, Bruce C, Hill SE \& Read NW (1987) Duodenal and ileal lipid suppresses postprandial blood glucose and insulin responses in man: possible implications for the dietary management of diabetes mellitus. Clin Sci 72, 209-216.

Wolever TMS, Jenkins DJA, Collier GR, Lee R, Wong GS \& Josse RG (1988) Metabolic response to test meals containing different carbohydrate foods: 1. Relationship between rate of digestion and plasma insulin response. Nutr Res 8, 573-581.

Wolever TMS, Vorster HH, Bjorck I, Brand-Miller J, Brighenti F, Man JI, Ramdath DD, Granfeldt Y, Holt S, Perry TL, et al. (2003) Determination of the glycaemic index of foods: interlaboratory study. Eur J Clin Nutr 57, 475-482. 